\title{
DISTRIBUSI FREKUENSI KEHILANGAN GIGI BERDASARKAN KLASIFIKASI KENNEDY DITINJAU DARI TINGKAT PENDAPATAN MASYARAKAT KELURAHAN PEUNITI BANDA ACEH
}

Liana Rahmayani*, Poppy Andriany ${ }^{*}$

\begin{tabular}{c}
\hline Keywords: \\
Partial Edentulous, \\
Kennedy Classification, \\
Income Level
\end{tabular}

ABSTRACT

Background: The missing teeth are substantially can influence the whole of general and oral health quality. That also can be the oral health indicator in a population. Partial edentulous teeth is a missing condition of one or several teeth that can cause the loosing of function which causing by a disease or specific condition. Kennedy classification is to classify the state division of some missing teeth include bilateral posterior Kennedy class I edentulous area (free end), Kennedy class II posterior unilateral edentulous area, Kennedy class III unilateral or bilateral edentulous (bounded), class IV Kennedy Single Edentulous Area used as the reference of anterior to see partial missing teeth area. Purpose: The study aims to see the frequency distribution of partial edentulous based on the Kennedy classification with income levels at the Peuniti Village society in Banda Aceh aged 35-44 years. Method: The study began the selection of the subject at the Peuniti Village in Banda Aceh with missing teeth oral examination and fill the questionaire. The study was using univariate analysis to see the frequency distribution of missing teeth in subject at Peuniti Village Banda Aceh. Result: The result showed that partial edentulous based on the Kennedy classification with income level at Peuniti Village society in Banda Aceh was higher in class III and found at age 35-44 years.

\section{PENDAHULUAN}

Kehilangan gigi secara keseluruhan dapat mempengaruhi kualitas kesehatan umum dan mulut. Kehilangan gigi sebagian dapat dikarenakan penyakit jaringan keras dan jaringan lunak. Penyakit jaringan keras gigi yang paling sering terjadi adalah karies gigi, sedangkan penyakit jaringan lunak merupakan penyakit yang sering terjadi pada jaringan lunak pendukung gigi geligi ${ }^{1}$. Selain penyakit jaringan lunak dan jaringan keras gigi, faktor sosial ekonomi juga mempengaruhi kehilangan gigi sebagian, yang meliputi pendidikan, pendapatan dan pekerjaan seseorang ? Ettinger RL dkk (2001), Pallegerada C (2005) menyatakan bahwa masyarakat yang berpendidikan tinggi lebih sedikit mengalami kehilangan gigi sebagian dari pada masyarakat yang berpendidikan rendah ${ }^{3,4}$.
Ayodeji dkk (2004) menyatakan bahwa tingkat sosial ekonomi yang rendah memiliki lebih banyak kehilangan gigi, dikarenakan masyarakat yang tingkat sosial ekonominya tinggi memiliki lebih banyak informasi tentang kebutuhan kesehatan gigi, dan segera mungkin merawat kesehatan giginya dari pada masyarakat yang tingkat sosial ekonominya rendah, yang akan merawat kesehatan gigi mereka pada saat sakit saja ${ }^{5}$. Gilbert dkk (2003) mengemukakan bahwa kehilangan gigi berhubungan dengan tingkat pendapatan, orang-orang yang tingkat pendapatan rendah mempunyai resiko kehilangan gigi lebih tinggi dari pada masyarakat yang tingkat pendapatannya tinggi yang memiliki lebih sedikit kehilangan gigi ${ }^{6}$.

Berdasarkan berbagai macam faktor kehilangan gigi, para ahli mengklasifikasikan daerah kehilangan gigi sebagian, salah

* Fakultas Kedokteran Gigi Universitas Syiah Kuala - Darussalam Banda Aceh

Korespondensi: liana.rahmayani@yahoo.com 
satunya Kennedy mengklasifikasikan daerah kehilangan gigi sebagian menjadi empat macam klas keadaan tidak bergigi, yaitu Klas I Kennedy Bilateral Posterior Edentulous Area (free end), Klas II Kennedy Unilateral Posterior Edentulous Area, Klas III Kennedy Unilateral or Bilateral Edentulous (bounded), dan Klas IV Kennedy Single Edentulous Area Anterior. Klasifikasi Kennedy ini banyak digunakan karena menunjukkan dengan jelas dan cepat jenis keadaan tidak bergigi. Prabhu dkk (2009) juga menyatakan dari hasil penelitiannya bahwa Klas III Kennedy adalah yang paling umum ditemukan pada usia 35-44 tahun, hal ini dikarenakan hasil dari penelitian yang dilakukan oleh WHO menyatakan bahwa masyarakat dengan usia 35-44 tahun adalah yang paling banyak ditemukannya kehilangan gigi sebagian 7 .

Tujuan penelitian adalah untuk mengetahui distribusi frekuensi kehilangan gigi sebagian berdasarkan klasifikasi Kennedy ditinjau dari tingkat pendapatan pada masyarakat Kelurahan Peuniti Banda Aceh yang berusia 35-44 tahun.

\section{METODE PENELITIAN}

Jenis penelitian yang digunakan dalam penelitian ini adalah survei deskriptif yang dilaksanakan di Kelurahan Peuniti Banda Aceh ${ }^{8}$. Populasi dalam penelitian ini adalah seluruh masyarakat Kelurahan Peuniti Banda Aceh dengan subjek yang sesuai kriteria inklusi antara lain subjek laki-laki dan perempuan yang berusia 35-44 tahun, kooperatif dan mengalami kehilangan sebagian gigi.

Penelitian ini menggunakan pendekatan kualitatif dengan metode penelitian survey, yaitu penelitian yang mengambil sampel dari suatu populasi dengan menggunakan kuisioner sebagai alat pengumpul data dan pemeriksaan kehilangan sebagian gigi pada masingmasing subjek penelitian. Penentuan subjek menggunakan teknik Purposive Sampling dengan jumlah subjek sebanyak 100 orang ${ }^{9}$.

Pada penelitian ini alat dan bahan yang dipakai antara lain: kaca mulut, masker, kapas, handskun, alkohol, lembar kuesioner, formulir informed consent, dan alat tulis. Data yang diambil bersumber dari data primer yang langsung diambil dari subjek penelitian.

Setelah mendapatkan izin penelitian dari kepala Kelurahan Peuniti Banda Aceh dan calon subjek, kemudian dilanjutkan dengan penjelasan maksud dan tujuan penelitian, lalu diikuti dengan pengambilan data yang dilakukan dengan membagikan kuisioner yang terdiri dari pertanyaan pribadi misalnya nama, alamat, usia dan sebagainya. Kuisioner dilakukan secara tertulis sebelum dilakukan pemeriksaan kehilangan gigi untuk melihat adanya kehilangan gigi menurut klasifikasi Kennedy.

\section{HASIL PENELITIAN}

Penelitian ini dilakukan di Kelurahan Peuniti Banda Aceh pada bulan Januari 2011. Subjek penelitian dipilih sesuai kriteria inklusi dengan cara pemeriksaan kehilangan gigi dan memberikan kuesioner berupa pertanyaan mengenai tingkat pendapatan. Subjek berjumlah 100 orang, yang terdiri dari 53 (53\%) laki-laki dan 47 (47\%) perempuan.

Subjek terbagi kedalam 2 kelompok yaitu pendapatan tinggi dan pendapatan rendah. Jumlah subjek dengan pendapatan tinggi sebanyak $73(73 \%)$ subjek, sedangkan pendapatan rendah sebanyak $27(27 \%)$ subjek. Data subjek yang telah diteliti ditabulasi dalam tabel distribusi sebagai berikut (tabel 1). 
Tabel 1. Distribusi Jumlah Subjek Berdasarkan Daerah Kehilangan Gigi menurut Klasifikasi Kennedy pada Rahang Atas.

\begin{tabular}{|c|c|c|}
\hline Klasifikasi Kennedy & N & Jumlah (\%) \\
\hline Klas I & 22 & 22.0 \\
\hline Klas II & 19 & 19.0 \\
\hline Klas III & 52 & 52.0 \\
\hline Klas IV & 7 & 7.0 \\
\hline Total & 100 & 100.0 \\
\hline
\end{tabular}

Hasil yang diperoleh pada Tabel 1, rahang atas menunjukkan persentase kehilangan gigi berdasarkan Klasifikasi Kennedy di Kelurahan Peuniti Banda Aceh. Jumlah terbanyak adalah subjek dengan klasifikasi kehilangan gigi kennedy klas III yaitu sebesar 52 orang (52\%).

Tabel 2. Distribusi Jumlah Subjek Berdasarkan Daerah Kehilangan Gigi menurut Klasifikasi Kennedy pada Rahang Bawah.

\begin{tabular}{|c|c|c|}
\hline Klasifikasi Kennedy & N & Jumlah (\%) \\
\hline Klas I & 19 & 19.0 \\
\hline Klas II & 21 & 21.0 \\
\hline Klas III & 52 & 52.0 \\
\hline Klas IV & 8 & 8.0 \\
\hline Total & 100 & 100.0 \\
\hline
\end{tabular}

Hasil yang diperoleh Tabel 2. pada rahang bawah persentase kehilangan gigi berdasarkan Klasifikasi Kennedy di Kelurahan Peuniti Banda Aceh terbanyak subjek dengan Klas III Kennedy sebanyak 52 orang (52\%), dan persentase terkecil subjek dengan Klas IV Kennedy sebanyak 8 orang (8\%).

Tabel 3. Distribusi Jumlah Subjek Berdasarkan Tingkat Pendapatan di Masyarakat Kelurahan Peuniti Banda Aceh.

\begin{tabular}{|c|c|c|}
\hline Pendapatan & N & Jumlah (\%) \\
\hline Tinggi & 73 & 73.0 \\
\hline Rendah & 27 & 27.0 \\
\hline Total & 100 & 100.0 \\
\hline
\end{tabular}

Hasil yang diperoleh pada Tabel 3. menunjukkan persentase berdasarkan tingkat pendapatan di Kelurahan Peuniti Banda Aceh, dengan tingkat pendapatan tinggi sebanyak 73 subjek $(73 \%)$ dan tingkat pendapatan rendah sebanyak 27 subjek (27\%).

Hasil yang diperoleh dari Tabel 4. tabulasi silang kehilangan gigi sebagian berdasarkan klasifikasi Kennedy pada rahang atas dengan tingkat pendapatan di Kelurahan Peuniti Banda Aceh dengan total subjek lebih tinggi pada tingkat pendapatan tinggi sebanyak 73 orang, sedangkan subjek dengan tingkat pendapatan rendah jumlah subjeknya lebih sedikit yaitu sebanyak 27 orang. Persentase berdasarkan klasifikasi kehilangan gigi jika dilihat dari pendapatan, baik pada pendapatan tinggi maupun pendapatan yang rendah jumlah subjek yang terbanyak yaitu pada klas III Kennedy sebanyak 41 subjek yang berpendapatan tinggi, dan 11 subjek dengan pendapatan rendah.

Tabel 4. Tabulasi Silang Kehilangan Gigi Sebagian Berdasarkan Klasifikasi Kennedy pada Rahang Atas dengan Tingkat Pendapatan di Kelurahan Peuniti Banda Aceh

\begin{tabular}{|c|c|c|c|c|c|}
\hline \multirow{2}{*}{$\begin{array}{c}\text { Tingkat } \\
\text { Pendapatan }\end{array}$} & \multicolumn{4}{|c|}{ Klasifikasi Kennedy } & \multirow{2}{*}{$\begin{array}{c}\text { Jumlah } \\
\text { Subjek }\end{array}$} \\
\cline { 2 - 5 } & Klas I & Klas II & Klas III & Klas IV & 73 \\
\hline Tinggi & 16 & 12 & 41 & 4 & 27 \\
\hline Rendah & 6 & 7 & 11 & 3 & 100 \\
\hline Total & 22 & 19 & 52 & 7 & \\
\hline
\end{tabular}


Tabel 5. Tabulasi Silang Kehilangan Gigi Sebagian Berdasarkan Klasifikasi Kennedy pada Rahang Bawah dengan Tingkat Pendapatan di Kelurahan Peuniti Banda Aceh.

\begin{tabular}{|c|c|c|c|c|c|}
\hline \multirow{2}{*}{$\begin{array}{c}\text { Tingkat } \\
\text { Pendapatan }\end{array}$} & \multicolumn{4}{|c|}{ Klasifikasi Kennedy } & Jumlah \\
\cline { 2 - 5 } & Klas I & Klas II & Klas III & Klas IV & Subjek \\
\hline Tinggi & 15 & 17 & 38 & 3 & 73 \\
\hline Rendah & 4 & 4 & 14 & 5 & 27 \\
\hline Total & 19 & 21 & 52 & 8 & 100 \\
\hline
\end{tabular}

Demikian juga dengan hasil yang diperoleh dari tabel 5, tabulasi silang kehilangan gigi sebagian berdasarkan klasifikasi Kennedy pada rahang bawah dengan tingkat pendapatan di Kelurahan Peuniti Banda Aceh, baik tingkat pendapatan tinggi maupun pendapatan rendah jumlah subjek terbanyak yaitu pada kalsifikasi kennedy klas III, dengan jumlah 38 subjek pada pendapatan tinggi dan 14 subjek pada pendapatan rendah.

\section{DISKUSI}

Kehilangan gigi sebagian adalah kehilangan satu atau lebih gigi pada rahang atas atau rahang bawah, dapat juga didefinisikan sebagai suatu kondisi dimana satu atau beberapa gigi terlepas dari soketnya dan acuan untuk mengukur daerah kehilangan gigi sebagian adalah dengan klasifikasi Kennedy (1923) yaitu Klas I Kennedy Bilateral Posterior Edentulous Area (free end), Klas II Kennedy Unilateral Posterior Edentulous Area, Klas III Kennedy Unilateral or Bilateral Edentulous (bounded), Klas IV Kennedy Single Edentulous Area Anterior ${ }^{7,10 .}$

Pola kehilangan gigi adalah struktur kehilangan gigi yang diklasifikasikan atas kehilangan gigisebagian berdasarkan Klasifikasi Kennedy. Kehilangan gigi baik sebagian atau seluruhnya dapat menjadi indikator kesehatan mulut suatu populasi dimana jumlah kehilangan gigi merupakan penilaian dari sukses atau tidak suatu prosedur pencegahan dan perawatan kesehatan gigi geligi ${ }^{2}$.

Berdasarkan hasil penelitian ini terlihat bahwa persentase kehilangan gigi sebagian Klas III lebih banyak ditemukan di rahang atas pada usia 35-44 tahun, yaitu sebesar 52 (52\%) subjek, dengan 41 (41\%) subjek yang tingkat pendapatan tinggi dan 11 (11\%) subjek yang tingkat pendapatan rendah. Begitu juga dengan rahang bawah, persentase daerah kehilangan gigi sebagian klas III Kennedy lebih banyak ditemukan pada usia 35-44 tahun, yaitu sebesar 52 (52\%) subjek, dengan 38 (38\%) subjek yang tingkat pendapatan tinggi dan 14 (14\%) subjek dengan tingkat pendapatan rendah. Hasil penelitian ini sesuai dengan penelitian yang dilakukan oleh Prabhu dkk (2009), yang menyatakan bahwa kehilangan gigi sebagian klas III Kennedy lebih banyak dijumpai pada usia 35-44 tahun ${ }^{7}$.

Pada penelitiannya Prabhu dkk juga menemukan kehilangan gigi sebagian paling banyak ditemukan pada rahang bawah dibandingkan rahang atas, hal ini disebabkan gigi molar permanen rahang bawah adalah gigi yang pertama erupsi di rongga mulut sehingga memungkinkan persentase karies yang tinggi dan kemungkinan dicabut akan lebih cepat ${ }^{\text {? }}$. Akan tetapi pada penelitian ini menunjukkan hasil yang berbeda dimana dijumpai kehilangan gigi sebagian baik di rahang atas maupun di rahang bawah hasilnya adalah sama yaitu sebesar $52 \%$.

Lopez dkk (2006) dan Braine dkk (2005) pada penelitiannya menemukan bahwa gambaran kehilangan gigi sebagian 
dengan tingkat pendapatan pada masyarakat pendapatan tinggi, cenderung memiliki kesadaran untuk memperbaiki kesehatan rongga mulutnya, menggunakan fasilitas kesehatan gigi dan mulut serta gaya hidup yang lebih baik untuk memperbaiki kesehatan rongga mulut. Umumnya masyarakat dengan tingkat pendapatan yang tinggi mempunyai tingkat pendidikan yang tinggi pula, sehingga dapat melakukan perawatan gigi dan mulut sesuai dengan anjuran dokter gigi dibandingkan dengan tingkat pendapatan yang rendah ${ }^{11,12}$.

Melihat dari hasil penelitian yang dilakukan oleh Lopez dkk (2006) dan Braine dkk (2005), tidak begitu sesuai dengan hasil penelitian ini, yang mana walaupun pada masyarakat dengan pendapatan tinggi tetapi pengetahuan dan kepedulian masyarakat mengenai kesehatan gigi dan mulut masih kurang. Serta anggapan yang menilai bahwa kebutuhan perawatan kesehatan gigi dan mulut menghabiskan biaya yang mahal juga diduga menjadi masalah di masyarakat tersebut. Pada Penelitian ini juga ditemukan bahwa rata-rata beban tanggungan di dalam keluarga yang cukup besar, sehingga pendapatan yang diterima belum cukup memadai walaupun tingkat pendapatan tergolong tingkat pendapatan tinggi. Semakin banyak jumlah anggota keluarga akan menyebabkan pengeluaran semakin banyak yang akan berakibat pada kecukupan pendapatan setiap bulan, sehingga masyarakat berpikir panjang untuk melakukan perawatan giginya.

\section{KESIMPULAN}

Hasil distribusi frekuensi kehilangan gigi sebagian berdasarkan klasifikasi Kennedy ditinjau dari tingkat pendapatan pada masyarakat Kelurahan Peuniti di Banda Aceh menunjukkan bahwa persentase kehilangan gigi Klas III Kennedy lebih banyak ditemukan pada usia 35-44 tahun yaitu sebesar 52\% pada rahang bawah dan $52 \%$ pada rahang atas. Jumlah subjek yang kehilangan gigi sebagian pada tingkat pendapatan tinggi lebih besar yaitu sebanyak 73 subjek (73\%) dan sebanyak 27 subjek (27\%) pada tingkat pendapatan tinggi rendah. Saran dari hasil penelitian ini antara lain: diharapkan kepada peneliti lain dapat melakukan penelitian pada tempat penelitian yang berbeda dan jumlah subjek yang lebih banyak, dengan tujuan sebagai bahan perbandingan hasil penelitian agar dapat digunakan sebagai bahan masukan pengembangan ilmu dalam kaitannya dengan kajian bidang kehilangan gigi. Diharapkan pada instansi terkait seperti Dinas Kesehatan agar dapat meningkatkan informasi kepada masyarakat khususnya masyarakat Kelurahan Peuniti Banda Aceh melalui pihak kelurahan mengenai menjaga kesehatan gigi dan mulut, dan sesegera mungkin menggantikan gigi yang hilang dengan gigi tiruan agar memperbaiki fungsi yang hilang akibat pencabutan gigi dan lain sebagainya.

\section{DAFTAR PUSTAKA}

1. Depkes RI. Pembangunan Pelayanan Kesehatan. Jakarta: 2004.

2. Demographic and Economic Factor Affecting the Acceptance of Removable Dentures Turkey. Eur J Dent 2007;2:104-110.

3. Ettinger RL, Beck JD, Jakobsen J. Removable prosthodontic Treatment needs. A Survey. J Prosthet Dent 2001;51:419-427.

4. Pallegedara C,Ekanayake L. Tooth loss. The Wearing of Dentures and Associated Factors. An Srilankan Older Individuals. Gerondotology 2005;22:193-199.

5. Ayodeji Esan Temitope, Adeyemi oluniyi Olusile. Socio-Demographic Factors and Edentulisme : the Nigerian Experience. BMC Oral Health 2004;4:3.

6. Gilbert Gregg H, Paul Duncan R, shalton Brent J, Social Determinants of Tooth Loss. Health Services Research 2003; 38:6.

7. Prabhu N, kumar S, D'sauza M, Hegde V. Partial Edentulousness in a Rural Population Based on Kennedy's classification : an Epidemiological Study. J Prosthodont 2009;9:22.

8. Harinaldi. Prinsip-Prinsip Statistik. Jakarta: Erlangga 2005.

9. Barlett, James E. dan Chadwick C. Higgins. 2001. "Organizational Research: Determining Appropriate Sample Size in Survey Research", Information Technology, Learning, and Performance Journal. Vol. 19 No. 1:43-50.

10. BPS Nanggroe Aceh Darussalam. Sistem Neraca Sosial Ekonomi Provinsi Nanggroe Aceh Darussalam. Banda Aceh, BPS NAD 2009:65-112. 
11. Lopez R. Baelum V. Gender Differences in Tooth Loss Among Shilean Adolescents: Socio-Economic and Behavoiral Correlates. Acta dontol Scand. 2006;54(3):169.

12. Braine T. More Oral Health Care Needed for Ageing Populations. J Dent Res. 2005;19:385. 